\title{
AS CONTRIBUIÇÕES DE MARIA REGINA SOARES DE LIMA PARA A CIÊNCIA POLÍTICA BRASILEIRA
}

Maria Regina Soares de Lima's contributions to Brazilian political Science

Marianna Albuquerque ${ }^{1}$

1 Doutoranda em Ciência Política no Programa de Pós-Graduação do Instituto de Estudos Sociais e Políticos da Universidade do Estado do Rio de Janeiro (IESP-UERJ). Bolsista do Conselho Nacional de Desenvolvimento Científico e Tecnológico (CNPq) . E-mail: marianna_raa@yahoo.com.br 


\title{
RESUMO
}

Este breve ensaio busca apresentar as principais contribuições da professora e pesquisadora Maria Regina Soares de Lima para a Ciência Política brasileira. São destacados temas como a inclusão da economia política nas análises de política externa, a caracterização da política externa como política pública e a importância da América do Sul para as Relações Internacionais do Brasil. No ano em que a tradição do Instituto de Estudos Sociais e Políticos da Universidade do Estado do Rio de Janeiro (IESP-UERJ) completa cinquenta anos, cabe ressaltar a contribuição teórica de uma intelectual que faz parte dessa história.

PALAVRAS-CHAVE: Maria Regina Soares de Lima; Ciência Política Brasileira; IESP-UERJ

\begin{abstract}
This brief essay aims to present the main contributions of professor and researcher Maria Regina Soares de Lima to the Brazilian Political Science field. Issues such as the inclusion of political economy in foreign policy analysis, the characterization of foreign policy as public policy and the importance of South America for Brazil's international relations are highlighted. In the year of the Institute of Social and Political Studies' 50th anniversary, it is worth mentioning the theoretical contribution of an intellectual who is part of this history.
\end{abstract}

KEYWORDS: Maria Regina Soares de Lima; Brazilian Political Science; IESPUERJ 


\section{INTRODUÇÃO}

No final da década de 1970, o Brasil vivia um período de transição. Anos de governos autoritários tinham levado brilhantes pesquisadores para a busca de uma vida em segurança fora do país, mas a abertura iniciada e pactuada para uma nova democracia trazia a esperança de dias melhores. As mudanças a nível nacional eram acompanhadas de oscilações individuais na vida dos acadêmicos que decidiram ficar e pesquisar em um contexto no qual, mais do que nunca, conhecimento era sinônimo de resistência. Entre eles, estava Maria Regina Soares de Lima. A pesquisadora permaneceu em instituições nacionais enquanto os colegas de profissão estavam saindo ao exílio, e partiu ao exterior exatamente no período em que os mesmos estavam voltando. A mobilidade internacional foi para cursar doutorado, que chegou ao fim com seu retorno em 1986, trazendo uma tese premiada e publicada em livro.

Para muitos, a tese de doutorado é o início de uma carreira promissora. Para Soares de Lima, a tese foi a confirmação de uma trajetória já brilhante como professora e pesquisadora no Brasil. Sua primeira casa foi o antigo Instituto Universitário de Pesquisas do Rio de Janeiro (IUPERJ), e esta ainda é sua instituição de trabalho, pois Soares de Lima passou por mais uma transição em sua história, ao ver o antigo IUPERJ ser transferido ao Instituto de Estudos Sociais e Políticos (IESP-UERJ). No meio do caminho, ainda se somaram vinte anos como professora da Pontifícia Universidade Católica do Rio de Janeiro (Puc-RJ), entre 1987 e 2010. Em paralelo, diversas carreiras foram construídas a partir de suas aulas e orientações.

Não são muitas pessoas que têm em sua trajetória pessoal os marcos de construção de um campo de conhecimento, e Maria Regina certamente é uma delas. Uma das professoras que leciona há mais tempo no IESP, considerando a época do IUPERJ, é também uma das mais humanas, generosas e empáticas da academia brasileira. Tantas características positivas no âmbito privado são acompanhadas de igual qualidade para o empenho profissional. Esse breve 
ensaio possui como objetivo, portanto, ressaltar as principais contribuições teóricas que Soares de Lima escreveu, criou e pensou, e que a transformaram em uma das grandes referências dos temas internacionais dentro da Ciência Política brasileira e mundial. Para tal, está estruturado em três aspectos centrais: 1. a economia política; 2. a política pública; e, 3. a América do Sul, a serem desenvolvidos abaixo.

\section{A ECONOMIA POLÍTICA DA POLÍTICA EXTERNA: QUANDO A TESE VIRA CÂNONE}

Em 1986, Soares de Lima defendeu sua tese de doutorado na Vanderbilt University, nos Estados Unidos, sob orientação do Prof. John Dorsey Jr. Na obra, a autora abordou um tema pelo qual o subcampo das Relações Internacionais é comumente criticado pelas demais áreas da Ciência Política: a ausência da economia nas análises. Pelas teorias clássicas, as interações entre os Estados no sistema internacional são direcionadas por explicações como o poder do Estado, seu relacionamento com os demais pares ou sua capacidade de produção normativa. Quando a economia entra na análise, normalmente esta relação é feita por chaves de leitura marxistas, que internacionalizam a abordagem. É nesse ponto que reside a inovação da autora: em The Political Economy of Brazilian Foreign Policy: Nuclear Energy, Trade and Itaipu (2013), Soares de Lima buscou na economia doméstica do Brasil os condicionantes para as opções de política externa.

A partir desse estudo, a autora inaugurou a verdadeira tese de sua tese: a política externa precisa ser estudada como política pública. Sui generis e com particularidades, certamente, mas é necessário abrir a caixa preta do Estado e olhar a interação dos princípios e valores tradicionais de atuação do país com a composição corrente dos atores, das agendas e dos interesses daqueles capazes de influenciarem os tomadores de decisão (Soares de Lima, 2000). É por meio dessa abordagem que atores não tradicionais como lobbies, empresariado, 
mídia, militares, academia e movimentos sociais passam a ser tema de estudo de gerações e gerações que se seguiram.

Não é só a configuração de forças externas - apesar destas não serem desprezíveis e, muitas vezes, vinculantes - que determina o curso escolhido. Soares de Lima considerou, em seu estudo, que a existência de um consenso entre as elites governantes também é um elemento que impacta o grau de comprometimento e envolvimento do país com a ordem externa. No Brasil, a resolução precoce dos problemas de fronteira fez com que as elites nacionais pensassem o país como uma "potência satisfeita", de vocação pacífica, o que deslegitimou os gastos militares e gerou pouco apoio às pretensões em temas de segurança internacional. Este aspecto relaciona-se com outra linha de estudos desenvolvida pela autora: a possibilidade de emergência dos Estados no sistema internacional.

\section{POTÊNCIAS EMERGENTES: QUAL O PAPEL DO BRASIL NO MUNDO?}

Quando a Guerra Fria acabou formalmente, após a dissolução da União Soviética, em 1991, os principais especialistas das Relações Internacionais começaram a elaborar análises sobre as mudanças que o fim da bipolaridade geraria. Soares de Lima (1996), nessa linha, debruçou-se sobre o que considerava como teses equivocadas sobre a ordem mundial no pósGuerra Fria. Entre as teorias aventadas pela literatura, a autora descontrói argumentos dados até então como verdade, mostrando, por exemplo, que a tese da utilidade decrescente da força militar não se sustenta em um mundo pós-nuclear, que a unipolaridade sob comando dos Estados Unidos dependeria de forte respaldo interno, e que estaria se formando um concerto entre potências, ao mostrar que são baixos os desincentivos a comportamentos unilaterais em uma ordem pretensamente multipolar.

Cabe ressaltar, ainda, a quarta tese esmiuçada no texto: a de que o fim da Guerra Fria teria gerado um aumento dos espaços comunitários e de 
cooperação no sistema. Segundo os defensores desse argumento, haveria novas oportunidades para países intermediários ascenderem no sistema. Soares de Lima pretende mostrar como o cálculo não é tão simples. Dois elementos já mencionados ajudam a explicar porque: a vontade de ascender depende das variáveis domésticas, e a economia política das relações abre ou fecha espaços para cada ascensão. Nas palavras da autora:

\begin{abstract}
Desta forma, a questão não é apenas a continuidade das instituições criadas no período da Guerra Fria ou mesmo a sua permanência, ainda que modificadas. O problema é como incidirão as questões distributivas na montagem de um novo arcabouço institucional, qualquer que seja ele. Como se sabe, os resultados de conflitos distributivos tendem a ser resolvidos, prioritariamente, pelo poder de barganha relativo dos atores envolvidos. Por outro lado, como já observado, a erosão da fronteira interno-externo, em função da interpenetração econômica, poderá levar à geração de uma carga adicional de conflitos distributivos entre países desenvolvidos, em especial com relação à escolha dos padrões a partir dos quais se fará a convergência econômica (LIMA, 1996: n.p.).
\end{abstract}

Esses conflitos distributivos do pós-Guerra Fria geraram novas estratificações entre os Estados no sistema, nivelando os espaços de ação prioritários das grandes potências, dos países intermediários e dos países pequenos. Inúmeros termos surgiram na literatura para classificar o estrato médio, do qual o Brasil seria parte. Foi a partir do diálogo com esta bibliografia que Soares de Lima enveredou por uma nova corrente de estudos: o papel das potências emergentes na reconstrução da ordem. Segundo a autora (2005), apesar de não haver consenso sobre a definição do termo, as potências emergentes possuiriam pelo menos um de três fatores identificáveis: capacidade material condizente, percepção do status e reconhecimento dos demais, sobretudo daqueles Estados considerados grandes potências.

Estes três fatores seriam indícios das diferenças do percurso de Brasil, China e Índia, por exemplo, nas últimas décadas. Se nos dois últimos havia significativa convergência entre elites sobre o papel de protagonista a ser (re)conquistado, o Brasil é um Estado em que o "consenso" sobre o que o país quer ser foi historicamente errante. As instabilidades foram marcadas pelas 
supramencionadas resolução precoce de fronteiras e falta de respaldo político para galgar voos maiores, em parte pelos problemas internos e pelo relacionamento diferenciado com o entorno regional imediato: a América do Sul.

\section{AMÉRICA DO SUL: CONTINENTE PACÍFICO?}

Novamente indo na contramão da produção literária, Soares de Lima questionava as afirmações de que o Brasil estava em um continente eminentemente pacífico. Tal posição apagaria uma vasta gama de debates políticos internos sobre qual rumo tomar nas relações regionais, desde a fundação da república, bem como colocaria nas sombras os conflitos existentes e atuais entre vizinhos. Ao mesmo tempo, por serem Estados intermediários ou pequenos, a melhor alternativa para os sul-americanos seria abraçar o regionalismo. De acordo com a autora:

\footnotetext{
No regionalismo estrutural ou pós-liberal, a região, concebida como integração física, produtiva e social supõe uma representação da mesma como um espaço de lugares nacionais, na concepção convencional de espaço geográfico. Como na maioria das regiões periféricas onde o legado colonial é marcante, na América do Sul todos os eixos de relacionamento e interação estão voltados para fora, para as antigas metrópoles e para os mercados desenvolvidos. A ideia de região embutida no conceito estrutural supõe a mudança da direção destes vetores de modo a fazê-los convergentes entre si, voltados para dentro da região (SOARES DE LIMA, 2010: p.5).
}

Foi no intuito de enfatizar a relevância e a importância da América do Sul enquanto agenda de pesquisa que Soares de Lima fundou, em 2003, o Observatório Político Sul-Americano (OPSA), que completou 15 anos de atividade em um seminário internacional, em 2018. Por meio das publicações e análises de conjuntura, formou-se uma rede de pesquisadores e alunos interessados em pesquisar a região e compreender os desafios da América do Sul no século XXI. 


\section{CONCLUSÃO}

No ano que o IESP-UERJ faz cinquenta anos, contando o tempo em que o instituto ainda era IUPERJ, o Brasil novamente encontra-se em um momento de transição. Nos ciclos de autoritarismo e redemocratização, resistiram as instituições e resistiram as pessoas. Entre estas, Maria Regina Soares de Lima aproveitou as adversidades para se reinventar. Fazer doutorado no exterior, quando poucos saiam do Brasil com data de retorno? Desafio aceito. Fundar um grupo de pesquisa sobre América do Sul, quando os Estados Unidos pareciam o grande tema? Por que não? Orientar alunos que querem estudar temas inovadores e desafiantes? "Não é pra isso que servem os professores?". Que o IESP-UERJ possa ter o legado de Soares de Lima pelos próximos cinquenta.

\section{REFERÊNCIAS}

LIMA, Maria Regina Soares de. (2013), The Political Economy of Brazilian Foreign Policy: Nuclear Energy, Trade and Itaipu. Brasília: Funag.

LIMA, Maria Regina Soares de. (2010), “Tradição e Inovação na Política Externa Brasileira”. Plataforma Democrática. Working Paper n. 3.

LIMA, Maria Regina Soares de. (2005), "A política externa brasileira e os desafios da cooperação Sul-Sul”. Revista Brasileira de Política Internacional, vol. 48, n.1, pp. 24-59, 2005.

LIMA, Maria Regina Soares de. (2000), "Instituições Democráticas e Política Exterior”. Contexto Internacional, vol. 22, n.2, pp 265-303, 2000.

LIMA, Maria Regina Soares de. (1996), "Teses Equivocadas sobre a Ordem Mundial do pós-Guerra Fria”. Dados, vol. 39, n. 3, 1996, n.p. 